\title{
MINIMALLY INVASIVE EXTRACARDIAC CONDUIT REPLACEMENT VIA A LEFT ANTERIOR SMALL THORACOTOMY
}

\author{
K. Imanaka, S. Takamoto, A. Murakami, and Y. Kaneko, Tokyo and Saitama, Japan
}

An extracardiac conduit is sometimes necessary in the repair of complex cardiac anomalies. However, it usually causes significant obstruction later and necessitates reoperation. Conduit replacement has been performed through a median resternotomy. This procedure may involve considerable risk and is highly invasive, since sternal re-entry is often difficult and extensive lysis of adhesions is required. Through a left anterior small thoracotomy (LAST), however, conduit replacement can be carried out quite safely, easily, and far less invasively.

Since 1998, 4 patients (1 male and 3 female patients, 13-18 years old) have undergone conduit replacement through a LAST. Their original cardiac anomalies were pulmonary atresia with ventricular septal defect in 2, tetralogy of Fallot with single coronary artery in 1 , and persistent truncus arteriosus in 1 . The conduits were in place for 6 to 17 years; 3 were xenopericardial rolls and 1 was a Dacron tube graft with a Hancock valve (Medtronic, Inc, Minneapolis, Minn). The pressure gradient was 44 to $90 \mathrm{~mm} \mathrm{Hg}$. Active infectious endocarditis was also present in 1 patient. New York Heart Association functional class was II in 2, III in 1, and IV in 1.

In all cases, the conduit was exposed safely and easily by opening the chest in the second intercostal space and dividing the second or third rib cartilage. The skin incision was 8 to 11 $\mathrm{cm}$ in length. After lysis of the adhesions just around the conduit, normothermic or mildly hypothermic cardiopulmonary bypass (CPB) was instituted via the right femoral artery and vein. In the last 2 patients, both arterial and venous cannulas were introduced percutaneously. While the heart was beating, the conduit was incised and resected. The main pulmonary artery was reconstructed with the fibrous tissue bed ${ }^{1}$ and a pedicled autologous pericardium or a strip of polytetrafluoroethylene patch.

The mean operation time was 5.1 hours (4.5-5.9 hours) and the mean CPB time was 2.1 hours (1.7-2.6 hours). All patients were extubated 3.1 hours later (1-5.5 hours), discharged from the intensive care unit on the next day, and discharged from

From the Department of Cardiothoracic Surgery, University of Tokyo, and First Department of Surgery, Saitama Medical School, Saitama, Japan.

Received for publication Aug 19, 1999; accepted for publication Aug 24, 1999.

Address for reprints: K. Imanaka, Saitama Medical School, 38 Morohongo, Moroyama-machi, Iruma-gun, Saitama 350-0495, Japan.

J Thorac Cardiovasc Surg 1999;118:1124-5

Copyright (C) 1999 by Mosby, Inc.

$0022-5223 / 99 \$ 8.00+0 \quad \mathbf{1 2 / 5 4 / 1 0 2 4 8 4}$ the ward 10 days later (8-11 days). Postoperative bleeding was negligible and the drainage tube was removed on the next day. Only 1 patient, who had preoperative severe anemia because of infectious endocarditis and prolonged antibiotic therapy, needed a homologous blood transfusion. In all cases, pulmonary stenosis was satisfactorily relieved, and all patients returned to New York Heart Association class I. The operation time, CPB time, intubation time, duration of chest drainage, intensive care unit stay, hospital stay, amount of blood loss and blood transfusion, and duration of persistence of systemic inflammatory response syndrome ${ }^{2}$ of these 4 patients were all significantly less than those of our previous patients with similar conditions, who had undergone conduit replacement through a median resternotomy $(P<.05$, MannWhitney nonparametric analysis).

Discussion. The LAST approach was effective for conduit replacement in these patients. Through a rather narrow surgical field, we could access the conduit directly and achieve satisfactory repair. As resternotomy and extensive lysis of adhesions was unnecessary, the operation was carried out safely, easily, and much less invasively even in patients in whom the ascending aorta or the conduit itself was located just beneath the sternum. Moreover, all patients convalesced rapidly and uneventfully.

Although recurrent stenosis caused by a conduit is progressive and is a widely known risk factor for poor late outcome ${ }^{3}$ conduit replacement has not been indicated unless severe stenosis or evident clinical symptoms developed. This was partly due to the risk and invasiveness of the procedure, which is greatly reduced when the LAST approach is adopted. Another factor is the possible recurrence of the stenosis. However, the long-term results of the method used here appear to be satisfactory. ${ }^{4}$ Even when stenosis recurs, catheter intervention can be much more effective for such a lesion than for a conduit stenosis. Therefore timely reoperation performed through a LAST can be expected to yield better long-term results and reduced surgical risks.

The LAST approach makes another scar in the skin. However, a reoperation through the same approach often requires a large incision. In view of the far less conspicuous and possibly less painful LAST scar and of the possible risks of the sternal re-entry, the addition of the LAST scar appeared to be well justifiable. Moreover, the LAST approach has many advantages. The surgical visibility is excellent. The laterally dissected pedicled autologous pericardium, which is a feasible material for repair, ${ }^{5}$ can be used more easily than through the midline approach. Of course, any kind of valve can be inserted if necessary. And sternal reclosure, which can cause unexpected compression or kink- 
ing of the new outflow tract, is unnecessary. We believe that these factors contribute to improvement of the quality of the repair. In conclusion, the LAST approach made conduit replacement much safer, easier, and less invasive. Because of the minimal risk and invasiveness, conduit replacement is more readily indicated, and long-term outcome in patients with an extracardiac conduit will be improved.

\section{REFERENCES}

1. Danielson GK, Downing TP, Schaff HV, Puga FJ, Di Donato RM, Ritter DG. Replacement of obstructed extracardiac conduits with autogenous tissue reconstruction. J Thorac Cardiovasc Surg 1987;93:555-9.

2. Members of the American College of Chest Physicians/Society of Critical Care Medicine Consensus Conference Committee.
American College of Chest Physicians/Society of Critical Care Medicine Consensus Conference: Definitions for sepsis and organ failure and guidelines for the use of innovative therapies in sepsis. Crit Care Med 1992;20:864-74.

3. Kirklin JW, Barratt-Boyes BG. Ventricular septal defect and pulmonary stenosis or atresia: results. In: Cardiac surgery. 2nd ed. New York: Churchill Livingstone; 1993. p. 919-37.

4. Cerfolio RJ, Danielson GK, Warnes CA, Puga FJ, Schaff HV, Anderson BJ, et al. Results of an autologous tissue reconstruction for replacement of obstructed extracardiac conduits. J Thorac Cardiovasc Surg 1995;110:1359-68.

5. Khoury W, Lang-Lazdunski L, Vernant F, Thibert M, Leca F. Pedicled pericardium for repair of right ventricular outflow tract and pulmonary arterial stenoses in tetralogy of Fallot: a sixyear experience. J Thorac Cardiovasc Surg 1996;112: 42432. 